\title{
FROM THE EDITORS:
}

\section{SPECIAL ISSUE ON RHYTHMS OF ACADEMIC LIFE}

There has been considerable discussion recently about the various ways in which the academic job and the academic career are changing. Advancing managerialism, greater emphasis on research achievement, rapid technological evolution, and the globalization of the industry are just a few of the influences on people working in academia. In this Special Issue, The Rhythms of Academic Life, we explore such trends and investigate their impact on the life and work of academics. We begin with brief introductions to the articles. We follow these by highlighting and expanding on the practical advice that can be extracted from the papers.

Multiple motivations lie behind the creation of this special issue on the rhythms of academic life and academic careers. First and foremost, anyone who has been in academia for any length of time will appreciate how working in the industry has changed. Gone are the rarified air of scholarly endeavor, the relaxed collegiality of university life, and the nurturing of the next generation's talent. In its place, many academics experience a permanent sense of dread and anxiety, a dehumanized managerial culture in which nothing is ever good enough, where faculty talk about an abstract alphabet of A stars, As, and Bs (or equivalent) and rarely about ideas, and are asked to service students whom universities regard as customers. This is the stark bifurcated tone of conversations in business school corridors and conferences whose veracity we wanted to explore. There is no doubt that there has been considerable change over the past couple of decades, but how far, how universally, in what ways, and what impact has there been on academic work and careers? These are the type of questions we wanted to answer. 
The second motivation for this special issue was to commemorate the 20th anniversary of the much-cited and fondly remembered compendium of contemplations on academic life entitled, Rhythms of Academic Life: Personal Accounts of Careers in Academia (Frost \& Taylor, 1996). The editors, Peter Frost and Susan Taylor, invited many leading voices in business education to reflect on their careers, transitions, and key elements of their jobs. The power of the book comes from the honesty and clear expression of the authors' critical reflections and the way they collectively defined the culture in business schools. Its anecdotal nature stimulated many informal discussions; however, empirical research on common challenges in academic careers is still rare. Our intention for this special issue was to create a forum for empirical work, for critical reflection on academic careers, and for substantive review of contemporary writings that have continued and extended Peter Frost and Susan Taylor's original efforts. In doing so, we hoped to generate a realistic contemporary picture of work in business schools and to spark more future research on academic careers.

A particular strength of Rhythms of Academic Life: Personal Accounts of Careers in Academia is the practical focus of most of its contributions. Many chapters were written for colleagues, typically junior and midcareer colleagues who are wondering how to navigate their academic careers. Reading about how people had overcome trials and tribulations to build successful careers gave the book an applied edge. In stimulating research on academic careers, our hope was that the resulting papers would provide evidence demonstrating useful strategies to influence academic career success. We are very happy to report that the articles included here do exactly that. After a brief introduction of the research articles, exemplary contribution and commentaries, and book reviews, and their theoretical contributions, we highlight and expand on the practical advice that can be extracted from them.

WHAT KEY PATTERNS IN ACADEMIC CAREERS ARE OBSERVED ACROSS THE CONTRIBUTIONS TO THE SPECIAL ISSUE? 
Given the enthusiastic response to the first versions of the papers, the issues covered seem to have struck a chord with readers of Academy of Management Learning \& Education. From these and from discussions with reviewers and others we have encountered on this journey, we have been able to pull out some general insights and lessons.

First, the overwhelming subtext to these discussions is that the culture of business schools has changed and is continuing to change toward more managerialism and all that entails. These changes are succinctly captured in Bill Harley's Exemplary Contribution and the various responses to it. Where there is divergence, it is about the degree to which these changes are positive or negative. We might have a nostalgia for a bygone era, and we might regret the loss of more relaxed (self-indulgent?) times, but perhaps we are now waking up to the reality that we are funded by the public purse and the crippling debts of students.

There is more consternation about how our performance is assessed and the way this is changing academic behavior. Following the mantra of "what gets measured, gets done," there is no doubting research output is more important than ever in terms of judging performance, influencing promotion, and determining who gets short-listed for jobs. Research performance is easily measured with journal rankings and impact factors, and research output is critical for accreditation, research exercises, and the ever-increasing numbers of institution and course rankings. Even though teaching and service loads may not have decreased, faculty are naturally skewing their efforts toward their research. We are experiencing a seismic change to research. Back in the day, academics published when they had something to say. Now they publish because they have to. If they don't, negative consequences flow: Increased teaching loads that make publication even more difficult, placement in a development track, or even the threat of losing their jobs. Given these existential pressures, faculty are adopting a wide range of strategies.

A natural response for many is to embark on research studies that can be completed quickly, easily, and cheaply. Harvesting low-hanging fruit may offset the worst existential 
threats, but these are not likely to be transformative studies or ones developed for the specific needs of organizations, both of which consume huge amounts of time and effort and are very difficult. Hence, we are seeing the proliferation of lots of incremental and theoretical work that contributes little and reduces the relevance of management research overall. And, on an individual level, these are unlikely to be the type of publication that propel a career or even create professional pride in its authors.

One of the ironies of the increasing focus on research output is that because more people are achieving success through this route, new criteria are appearing to differentiate academic performance. It is now taken for granted that successful academic staff will have a significant record of research publication. Those that haven't are already out of step with the transformation. The latest challenge for faculty is to establish their impact (Hughes, Webber, \& O’Regan, 2019). Although this word is notoriously difficult to define (Rawhouser, Cummings, \& Newbert, 2019), it is commonly interpreted to mean that faculty should contribute to the communities they serve, particularly businesses. It is a measure of the applied nature of academics' work, which comes as a shock given the necessarily narrow focus so many have developed to achieve publication in academic journals. Despite this contradiction, impact is not going away; it's becoming embedded in accreditation and ranking assessments. In part, the emergence of impact is a response to academics' own successful response to the "publish or perish" (Miller, Taylor, \& Bedeian, 2011) imperative. The advice for those developing new research projects or setting out on their research careers is to think about the practical benefits of their research at the outset and choose those topics that have a strongly applied nature.

Another strategy being applied more often is networking, particularly with networks comprised of people spread around the globe. Twenty years ago, email was in its infancy. Ten years ago, video conferencing was just emerging. But nowadays, these technologies are stable and being used by academic staff to facilitate research networks. When the contributions to 
Rhythms of Academic Life were being written in the early-1990s, networking in the sense of coming together to write papers was largely with colleagues at your own university or local universities, or people you had established relationships with, perhaps doctoral supervisors or people with whom you were at university, and occasionally people you met at conferences. But with electronic document transfer made easy through email and video conferencing facilitating face-to-face meetings, the academic environment has become truly global, and international barriers to research collaboration have largely evaporated. Now, a scholar without local collaborators need just write emails inviting relevant people to join a project. There are no guarantees that people will accept such invitations, but nevertheless, academics are using global research collaborators to forge careers. The lesson is to think global and to make efforts to collaborate with the people you need to collaborate with, not just those who happen to be handy. This advice is particularly relevant to junior colleagues and for those starting out on their careers. If you have just completed a doctorate, you should be at the cutting edge of the field, and you can use this currency to entice more senior people to work with you, especially if you are offering to do the bulk of the writing or data gathering!

In addition, there is a trend toward more international academic careers, and we see many more academics considering an international assignment at some point. As work in this special issue shows, these international moves can be highly rewarding for faculty. At the same time, researchers need to be aware of the challenges that are inherent in adapting to a different academic setting, potentially in a different language context, with different requirements for research productivity, teaching, and service. The transition from one system to another can mean a temporary reduction of research productivity. However, it seems that the networking effect with faculty in other countries can be highly beneficial in the long-run.

The globalizing of the academic mindset is influencing the relationship between the individual member of staff and their university. Jobs and careers are global, and the currencies of success are research publication, research grants, and impact. Although these things align 
with what most universities want, it is not an exhaustive list of what your institution hopes to extract from you. In the "flexible" world of deans and heads of department, they want you to cover the teaching of that member of staff who's off sick and to serve on the ethics committee. But if you are thinking globally, focusing on your own career, where are the longterm rewards for these things? In interviews, you will need to demonstrate you are competent in the classroom, that you are willing to take on service roles, and that you are someone people want to work with, but where the rubber hits the road, it's your research record that makes the difference. Hence, if you are focused on a career as an academic, as opposed to one in administration, and you are instrumental about it, those additional teaching and service opportunities might be ones to consider very carefully and take on judiciously.

There is an important caveat here. Many successful academics are passionate about their subjects, not only research, but also teaching and enthusing the next generation about the topic, consulting on it and influencing policy and action, and taking on service roles to advocate for it as well. You are always going to benefit from doing these activities well, and we are not suggesting for one moment that you shouldn't put your heart and soul into teaching and service activities; just don't overdo it. Universities may get the vast majority of their money from teaching, but in the current climate, your career advances from the research side of your CV. Treat teaching and service as necessary components of your job, but wake up each morning and say to yourself that you are going to your research job, which also requires you to teach and serve. Don't think of research filling the cracks between teaching and service duties, but vice versa.

\section{THEORETICAL CONTRIBUTIONS AND FUTURE RESEARCH DIRECTIONS}

One of the statements we hear repeatedly is “don't do research on academics or on academia. It is not worth your while and it isn't publishable." We beg to differ. As such, another important motivational drive for this special issue was to demonstrate that research on academic careers is useful, important, and worthwhile. In fact, there are several important 
features of academia and academic careers that make them useful for the exploration of a wide range of research topics that our different management discipline areas are interested in. Moreover, this intersection creates a range of unique opportunities for theory building and testing. As such, rather than shying away from research on academia or shunning it from our journals, we should embrace it.

The first useful feature is that the job of an academic includes at least four distinct job roles, that is, research, teaching, administration, and leadership. Sometimes, we can add counselor, entrepreneur, consultant, advocate, and several other roles. Very few other jobs we know of hold such a wide range of diverse responsibilities. In addition, the knowledge, skills, and abilities (KSAs) required to fulfill these responsibilities are often quite varied, and it is rare that an academic member of staff holds all of the required KSAs. This characteristic of academic careers should be of interest to researchers studying a variety of different topics in organizational behavior (OB) and human resource management (HRM), such as role overload and conflict, competing identities, identity management, work-life balance and conflict, burnout, emotional labor, person-environment fit, multitasking, and many other topics. For academic careers in particular, the diverse roles often stand in direct conflict with each other. For example, time spent on teaching or administration means less research productivity, which often has a stronger negative impact on career progression than the former two roles. Several articles here show that female academics and early-career academics are affected more severely by such issues. One such is Bristow, Robinson, and Ratle (2019), who examine how the identity construction of early- career academics is affected by the regulatory culture of business schools (i.e., publication counting, teaching evaluation, taking on administrative roles early, etc.). Their article provides novel insights for how rhythms in academic life affect identity work and illustrates how academic careers serve as an excellent environment for studying mainstream OB and HRM matters. 
Academic careers provide a fertile ground for studying a variety of theories in careers research, such as career ecosystems, career shocks, life course theory, career development theories, and many more. As our articles here demonstrate, academic careers in management at this time are characterized by global mobility, competitiveness, a volatile labor market, career and job uncertainty, increased casual employment, increased pressures for self-funding through consultancies and research grant applications, and a less certain pathway from receiving a degree to going into employment, just to name a few. As such, academic careers may be a particularly suitable context to study the effects of globalization on careers, the effects of a gig economy and project-based work, labor market changes, labor law changes, or changes in career progression over time. For example, Kraimer, Greco, Seibert, and Sargent (2019) explore career shocks as an influence factor on academic careers and assesses their impact at different career stages. Sandhu, Perera, and Sardeshmukh (2019) examine different career trajectories and their drivers, offering a new model of academic career pathways. And Belkhir et al. (2019) explore the effect of academic isolation (both geographic and nonmainstream) on the careers and experiences of early-career academics (ECAs), highlighting necessary mechanisms for professional engagement and career support.

This special issue also demonstrates the relevance of the academic career setting for international business (IB) research. The increasingly global nature of higher education means that academics deal with more international students in their classroom. They compete against other academics worldwide for jobs, journal space, and resources. And they are affected by business school expansions into foreign education markets; for example, when their university decides that they want to model themselves after and compete with leading institutions in other countries. In addition, the articles here show that academics are now more globally mobile and incorporate working in other academic systems into their careers. These aspects of career internationalization provide interesting opportunities for studying research questions related to expatriation, foreign language use and its consequences, global project work and 
collaborations, and global pressures through standardization of expectations (e.g., for publishing in a small set of top journals). Pudelko and Tenzer (2019) examine the impact of language as a barrier to international academic careers, highlighting specifically the role of expatriation, global mobility, and the internationalization of academia. Ryazanova and McNamara (2019) examine the impact of global mobility on publication outcomes and career progression, offering unique insights for the differential effects that global mobility can have at different career stages.

Finally, we also see rich research opportunities for organization theory (OT) research. For example, academic systems are no longer restricted to their own societal boundaries. This means that academia in one country no longer only needs to fulfill the societal purpose defined in that country; rather, academic institutions commonly set themselves international benchmarks beyond their national societal responsibilities. The result is that we see more standardized pressures on academics with regard to expectations for publication outputs, acceptable publication outlets, assessment of teaching quality or student evaluations of teaching, and pressures regarding acceptable and preferred epistemologies and ontologies and the resulting homogenization of thought and endorsed research topics. It would be fascinating to see, for example, a more systematic evaluation of research misconduct with the identification of the associated institutional and vocational pressures and an examination of the organizational context factors that create it, and not just another evaluation of researcher traits or motivations. We get an inkling of the research possibilities here from Pudelko and Tenzer (2019), who evaluate differences in national academic systems and their effect on academic careers. In addition, Bristow et al.'s (2019) examination of changes in the nature of higher education, in particular the increasingly common audit culture of business schools, and their impact on the life of ECAs provides an excellent example of the possible research opportunities. 
These are a few examples of research areas that could benefit from more frequent incorporation of the academic vocation into choices of study setting in OB, HRM, international management, and OT research. Academic career research is not a niche area, but one where mainstream research questions can be answered. It should not be viewed as selfindulgence or navel-gazing (we have heard that one before as well). Rather, we should look at our profession as we look at other professions. We should ask ourselves: "What are the interesting characteristics of this profession that allow us to study our research questions especially well?" And then we should go and do it.

\section{HOW DID SCHOLARS RESPOND TO OUR CHALLENGE?}

\section{Research Papers}

This special issue begins with six empirical papers exploring different aspects of academic careers. In "An investigation of academic career success: The new tempo of academic life" Kraimer, Greco, Seibert, and Sargent (2019) develop a model of academic career success based on the job demands-resources model. Conducting a survey study on a sample of Academy of Management members, the authors identify a range of job demands and resources that correlate with career satisfaction through the facilitating mechanism of work engagement. Most importantly, Kraimer et al. (2019) apply the concept of career shocks to academic careers. These career shocks are significant events in an academic's life that can have positive and negative effects (such as publishing a paper in a top-tier journal, receiving a research grant, or experiencing a negative political event, such as being denied tenure). Kraimer et al.'s (2019) study evaluates the differential role that these career shocks play. In addition, the authors examine the role of family interference with work conflict and find that it has a negative effect on work engagement and subsequently on career satisfaction. An interesting aspect of this work is that Kraimer et al. (2019) analyze the effects of job demands and resources at different career stages, showing that some job demands have a negative effect on career success for academics at certain career stages, but not at others. This is an 
important insight. Administrative decision-makers in departments need to be aware of the differential effects that certain tasks can have for academics at different career stages.

Diving deeper into academic career pathways, Sandhu, Perera, and Sardeshmukh (2019) provide an in-depth case study of five leading academics to uncover different routes to academic success in "Charted Courses and Meandering Trails: Crafting Success and Impact as Business School Academics.” All five academics are widely published and cited and leaders in professional associations. The paper further identifies common threats to academic careers, for example, threats related to undermining, politicizing, and discrimination. The main conclusion is that academics don't need to follow the mainstream, structured course charted for them by their universities and departments. Equally viable are career trails that form organically, taking advantage of different opportunities and developments that may offer little guarantee of paying off. Both the structured and the organic pathway can lead to career success. It is more important to stay authentic to one's own style of working, work hard, persist in the face of adversities, and believe in continuous growth and development. This indeed is encouraging news for junior academics who may fear that the academic spaghetti factory, so often portrayed as the ideal career path model during junior faculty consortia, is not for them. We hope that academic advisors use the insights from this study to assuage their doctoral students and junior colleagues' concerns that straying from the main path would lead to career suicide, and to support them with the more tailored advice presented by this study for making an organic career pathway work.

Assessing the career consequences of domestic and international mobility in "Choices and Consequences: Impact of Mobility on Research Career Capital and Promotion in Business Schools," Ryazanova and McNamara (2019) use data from 376 tenured faculty from 20 European business schools in 10 countries to link research productivity outcomes and speed of promotion with different mobility patterns. One finding is that international mobility increases research career capital but slows down academic promotion, especially for ECAs 
and for women. The authors further find that the right timing of international mobility is important. They identify a number of implications for senior academics advising early-career academics, such as the importance of publishing early in visible outlets and of socializing into professional communities. At the same time, Ryazanova and McNamara (2019) highlight that while international mobility has a positive effect on building career research capital, it is not a deterministic factor for academic success.

Staying with the topic of international mobility, Pudelko and Tenzer (2019) examine the impact of language as a barrier to international academic careers in "Boundaryless Careers or Career Boundaries? The Impact of Language Barriers on Academic Careers in International Business Schools." On the one hand, they examine the increasingly strong role that English proficiency plays in international careers, such as in publishing, teaching, and administrative tasks. On the other, they examine the role of operating in the language of the university at which one is employed. Interviewing academics from varied national backgrounds working in academic institutions in Germany, Finland, Japan, the UK, and the US, Pudelco and Tenzer (2019) identify the unique challenges of operating in these countries. In each country, proficiency in the native language differs in importance, and English proficiency among non-academic staff varies greatly. Pudelko and Tenzer (2019) thus identify how language proficiency, or the lack thereof, can create boundaries for career success. In addition, they also identify crucial career competencies that international academics should hone to operate successfully in different academic settings. In highlighting the important role that language proficiency in English as well as the local language plays, this study provides insights that academics should consider when planning an international career move.

In their paper, "Academic Arrhythmia: Disruption, Dissonance and Conflict in the Early-Career Rhythms of CMS Academics," Bristow, Robinson, and Ratle (2019) examine significant changes in the nature of higher education and their impact on the life of ECAs. In particular, they examine ECAs in critical management studies (CMS), a field that concerns 
itself with the nature and sources of power and oppression. The authors argue that critical management scholars, and in particular ECAs, reside at the margin of business schools because they study nonmainstream topics with nonmainstream methods, are often geographically on the periphery, and rarely fit the main mold of the "ideal" business school academic. Yet, their CMS background tends to make them more aware of and reflexive about the dynamics in their academic environment. The authors show how recent higher education changes are leading to rhythmic developments that create an arrhythmia in ECA's identities. Examining identity construction, the authors demonstrate how the rhythms enforced by the regulatory culture of business schools (i.e., publication counting, teaching evaluation, taking on administrative roles early, etc.) affect ECA's ongoing identity construction process and forces them to engage in deep identity work to cope with growing pressures. This identity work further increases their sense of insecurity. Bristow et al. (2019) point out that the audit culture of business schools has hit ECAs the hardest because they are still constructing their academic identities. The authors find that the most promising strategies to overcome the challenges posed by the audit culture are the most mentally and emotionally demanding and time-consuming. They suggest that business schools need to rethink how to engage ECAs who are on the margin as well as how they alleviate pressures resulting from administrative rhythms that have little academic merit.

Also focusing their attention on ECAs, in "Isolation in Globalizing Academic Fields: A Collaborative Autoethnography Early Career Researchers,” Belkhir, Brouard, Brunk, Dalmoro, Ferreira, Figueiredo, Huff, Scaraboto, Sibai, and Smith (2019) examine the challenges of isolation in one's academic field by employing an autoethnographic study of 10 ECAs. The authors assess how these ECAs cope with their isolation and identify three strategies that early-career researchers use to mitigate the effects of isolation. These are bricolage practices, polycentric governance practices, and integration mechanisms. This research has important implications for ECAs who operate in fields in which they may be 
isolated, for example, geographically or because others view their field as lacking legitimacy. This study also identifies several strategies that ECAs can use to manage their careers to overcome the effects of isolation, such as increasing personal visibility or establishing crossfield conversations. In addition, the authors highlight ways in which senior academics can support ECAs, a topic that Bill Harley further elaborates on in his Exemplary Contribution piece.

\section{Invited Contribution and Commentaries}

One of the beauties of Frost and Taylor's (1996) Rhythms of Academic Life: Personal Accounts of Careers in Academia is the way it started many conversations about the nature of the job. We wanted to mirror this conversational approach here. To do so, we commissioned Bill Harley to write a provocative essay capturing the current conversations commonly heard in the corridors of business schools and the conferences we attend. Once written, we invited multiple rejoinders directed toward particular themes and issues: relevance to the Asian context, equal opportunities, career choices, the quality of research, doctoral student training, and academic performance.

In his invited contribution, "Confronting the Crisis of Confidence in Management Studies: Why Senior Scholars Need to Stop Setting a Bad Example,” Harley (2019) describes the crisis of confidence running through management studies. Above the managerialist issues, he focuses on concerns about the value of management research, its narrowing focus, and the lack of impact that it has, and his worries about the way that teaching has been downgraded and underappreciated in business schools. Harley notes the transformation of traditional collegial academic cultures into more managerialist ones and argues that management scholars have a responsibility to address them. He proposes three practical steps that established management academics can take: First, management scholars should challenge and reject the notion that the research undertaken in business schools is directly comparable to that done in laboratory science. Second, management scholars should also challenge and 
reject the production grind culture forcing academics to churn out one paper after another. Third, management scholars should refuse to endorse the flawed way that academic performance is assessed. Harley's (2019) essay is a powerful and provocative piece with a positive call to action, especially for senior academics.

It is easy to think that the issues addressed by Harley (2019) are confined to the large "western" business schools of North America, Europe, and Australasia that have grown-up strongly influenced by U.S. and U.K. capitalist ideas. In his commentary, "Rejoinder to 'Confronting the crisis of Confidence in Management Studies: Why Senior Scholars Need to Stop Setting a Bad Example' From the Asian Perspective," Yoshikawa (2019) considers the culture in Asian business schools and shows that similar forces are at work there too with the pressure to publish on the rise, especially in those schools that want to compete globally. He notes that the single-minded pursuit of research excellence through publication needs to be accompanied with increased engagement of Asian management scholars in all aspects of the broader academic community.

In her commentary, “A More Feminine Scholarship: Relational Practice for Setting a Good Example,” González-Morales (2019) takes a diversity perspective in response to Harley's (2019) essay. Her primary focus is on the relational nature of academic work and how this is being eroded by the workaholic culture of the publication grind. She draws attention to the failure of the system to appreciate and reward relational work, which is at the heart of excellent teaching and research efforts. Her call to action is for relational work to be made visible and rewarded.

In responding to Harley's (2019) essay, Phillips (2019) challenges the second and third of Harley's recommendations. He notes that the publication process is a "winner-takesall" one in which there are no prizes for near misses, only accolades for the few successful people. In such a system, working hard is a prerequisite and a necessary precondition for success. Phillips has previously served as a dean and provides insight into the academic 
performance decisions in which he has been involved. He paints a picture of multifaceted assessment where the quality of journals in which people publish is just one component of performance management.

Extending Harley's (2019) call for experienced scholars to act, McKiernan and Tsui (2019) consider the legacy that the current generation of management academics are leaving in "Responsible Management Research: A Senior Scholar Legacy in Doctoral Education." Focusing on the implications for doctoral education, they argue scholars need to re-establish the higher calling of science, should help their doctoral students appreciate the relationship between science and society, and encourage others to become responsible servants and custodians of scientific knowledge.

As a conclusion to the discussion, in his commentary "Reflections on Academic Career Choices: What Might Have Been, What Is, and What May Yet Be," Cortina (2019) offers a personal reflection on his career choices and options that people might have if they decided that an academic career was no longer for them. In the first half of his rejoinder, Cortina (2019) asks the tough question of whether the grass is really greener in other jobs and professions. In the second half, he explores Harley's (2019) concerns about the nature of research and looks at how management academics might address some of these.

\section{Book Reviews}

The final section of this special issue is devoted to book reviews related to the complexity of living, working, and leading in the academy. Both Poirel (2019) and Spee (2019) review books focused on exploring ways of thinking about and experiencing the phenomenon of time. Poirel offers up an accessible review of Alhadeff-Jones' (2017) book devoted to temporal constraints using a framework from which readers may reflect on how to emancipate themselves from the pace of their work lives. Spee offers an enlightened review of Berg and Seeber's (2016) book that explores the neoliberal metaphor of the corporate university and 
associated pressures for productivity, efficiency, and compliance at the expense of time for reflection and deliberation in our teaching, research, and service work.

Chugh (2019), Stark (2019), and Koprowski (2019) present critical and informative reviews that challenge readers, especially those who manage and lead academics, to consider the competing perspectives of internal and external stakeholders. Chugh presents an in-depth review of Winter's (2017) book that offers an alternative to the managerialism dominating university administration by giving support to more relational, collegial, and collaborative approaches to empathetic leadership. Stark crafts a thorough review of Evans' (2018) empirical and critical study on academic leadership with a prescription for a renewed model of shared governance that provides meaningful opportunities to develop faculty and cultivate future contributions. Last, Koprowski offers a critical look into the world of academic rankings in his review of Sauder and Espeland's (2016) book on the systemic internal and external forces that continually pressure university administrators to achieve and maintain national and international recognition. While Sauder and Espeland's book is written in the context of law school rankings, Koprowski does a masterful job of transferring the concepts to the business school environment.

\section{WHAT PRACTICAL ADVICE CAN WE DISTILL FROM THE CONTRIBUTIONS?}

One advantage of conducting careers research is that it often has immediate impact for those working in the studied environment. That is certainly the case with this special issue, and in addition to the research implications discussed above, we are able to tease out practical advice for scholars at different stages of their careers:

\section{Late-Career Scholars}

Bill Harley's essay and the associated commentaries offer clear guidance to late-career scholars. On the one hand, they should be vocal in confronting the advancing managerialist cultures. They should be the people who have the experience and influence to fight this trend. Moreover, their seniority buffers them from the existential threat that confronting power 
might bring. What have they got to lose? On the other hand, their successful negotiation of their careers also puts them in the ideal place for mentoring more junior colleagues. Bearing in mind what worked over the past 30 or 40 years might not still hold true, they still have a lot to offer and can offer support and guidance. Simple advice: Mentor, mentor, mentor.

\section{Mid-Career Scholars}

The picture is more complex for mid-career scholars. They too have a mentoring role, especially through doctoral supervision and the support of junior staff. In addition, they should be holding senior staff accountable for their choices and take service positions to initialize change. Fighting from within for the culture you want is a lot more effective than Quixotic jousting from the outside. In managerialist cultures, the vocal outsider is easily dismissed as an annoying dinosaur whose time is past.

Networking is a key priority for many mid-career scholars. They should have the knowledge, skills, and experience that makes them valuable network partners to others, and their participation in high-quality networks should accelerate career progression. Impact is the new bugbear for many mid-career scholars. Is it a time to alter your research trajectory and seek out research projects likely to have significant impact? One such successful project could launch your career like nothing else.

\section{Early-Career Scholars}

Becoming an academic is an exciting moment. You have your doctorate, you're an independent researcher, you are going to influence young, eager, and bright minds, and the world lies at your feet. What's not to love? It is easy to get swept along on this tide of positive emotion. But before you know it, you're teaching a class of a thousand, you're under huge pressure to publish, and, worst of all, you accepted the Head of Department's "invitation" to join the ethics committee. The main lesson coming from the papers in this special issue is that you need a personal strategy: A clear idea of where you want to get to and how you intend to get there. Most of the time this will overlap with the needs of your institution, but not always. 
The important point may be to not look for the one best way to get promoted, but to look for your own way to build a career. In a recent Academy of Management professional development workshop on academic careers, Saku Mantere noted that by asking your Head of Department to explicitly define for you what criteria you need to fulfill to get promoted, you force this person to come up with a one-best-way, which then gets applied to you whether or not it fits you and your research. Essentially, by pushing your increased safety needs and discomfort with uncertainty on your Head of Department, you are creating your own (and others') straight-jacket. So, develop your own strategy to produce high-quality and highimpact research, do good teaching, and contribute to service maybe with a friendly and accomplished senior colleague or mentor who challenges you and is able to provide a bigger and more encompassing career perspective for you.

In addition, networks are crucial. Network like your life depends on it, because it does (your career, anyway). Although teams are formed for particular projects, teams that work stay together. The goal is to establish resilient networks that can work over multiple projects. If you have to be the glue keeping it together, then be that glue. A successful network greatly accelerates your career.

\section{Business Schools}

Although our focus has been on helping people with their academic careers, there is advice for business schools in the process. Quite simply, learn from HR and OB research and create a developmental and supportive culture. If you don't, good people will leave. This is a knowledge industry and ultimately research publications, research grants, and impact comes from the actions of the people you employ. One thing this special issue illustrates is that good people are in demand and will leave if treated poorly. Scholars are more willing than ever to consider international moves, making it a truly global market for academic staff. And the increased networking of academic staff provides them with more opportunities than ever before. So, rather than placing more restrictions on them, resist the urge to control staff. Work 
to create commitment to your university, school, and department by exploring how you can support their passions, initiatives, and projects. As they thrive, so will you. More than ever, this is a time when talented academics are looking for collegial places where they can grow, develop, and get the support they need.

\section{CONCLUSION}

Academic work and academic careers are exciting arenas for many aspects of management research beyond the traditional boundaries of career research. There is no theory of academic careers as such; instead, it is a setting in which many critical issues can be explored. As we have shown, the academic environment is one in which issues of careers intersect well with current research interests in OB, HRM, OT, and international management. The rapidly changing environment, the escalating demands placed on staff, and the increased internationalization of the profession all produce work and career issues for academics that the contributors to this special issue have explored. As pressures build on academic staff to conduct high-impact and industry-relevant research, one benefit of research in this area is the practical recommendations that tend to flow for people in the profession. As such, academic careers are a rich and fertile ground for high-impact research.

\section{REFERENCES}

Hughes, T., Webber, D., \& O’Regan, N. 2019. Achieving wider impact in business and management: Analysing the case studies from REF 2014. Studies in Higher Education, 44(4): 628-642.

Miller, A. N., Taylor, S. G., \& Bedeian, A. G. 2011. Publish or perish: Academic life as management faculty live it. Career Development International, 16(5): 422-445.

Rawhouser, H., Cummings, M., \& Newbert, S. L. 2019. Social impact measurement: Current approaches and future directions for social entrepreneurship research.

Entrepreneurship Theory and Practice, 43(1): 82-115.

Guest Editors

Jon Billsberry

Tine Köhler

Micheal Stratton 
Michael Cohen

M. Susan Taylor 